\title{
Caracterização dos Programas de Acompanhamento aos Jovens Egressos de Medidas Socioeducativas
}

\author{
Cibele Soares da Silva Costa ${ }^{1}$ \\ Maria de Fatima Pereira Alberto ${ }^{1}$ \\ ${ }^{1}$ Universidade Federal da Paraíba, João Pessoa, PB, Brasil. $\quad{ }^{1}$ Universidade Federal da Paraíba, João Pessoa, PB, Brasil.
}

Resumo: Este artigo tem como objetivo caracterizar os programas de acompanhamento aos jovens egressos de medida socioeducativa de internação (MSE). Participaram da pesquisa quatro membros de coordenação de programas de acompanhamento aos egressos de MSE de três estados brasileiros. Foi utilizada uma entrevista aberta individual cujos dados foram analisados a partir da Análise Temática de Conteúdo, de forma que se constatou as seguintes categorias: criação e implementação dos programas de acompanhamento aos egressos de MSE; funcionamento dos programas de acompanhamento aos egressos de MSE; e metodologia dos programas de acompanhamento aos egressos de MSE. Os dados analisados mostraram que os programas de acompanhamento aos egressos de MSE assumem características diferentes nos estados. Identificou-se também que os programas têm facilitado o acesso dos jovens acompanhados às políticas sociais, por meio da realização do trabalho em rede, baseado na incompletude institucional e na efetivação do Plano Individual de Atendimento. Conclui-se que a existência desses programas representa a continuidade das ações socioeducativas, mas eles necessitam de maiores investimentos que assegurem a permanência da oferta enquanto uma política universal, a partir do estabelecimento de um serviço de caráter continuado, com princípios, diretrizes e objetivos em âmbito nacional.

Palavras-chave: Medidas Socioeducativas, Egressos, Políticas Sociais, Juventude.

\section{Characterization of Follow-up Programs for Young Egresses from Socio-educational Measures}

\begin{abstract}
This article aims to characterize the follow-up programs for young egresses from socioeducational measures of internment (SEM). The study was conducted with four coordinators of follow-up programs for SEM egresses from three Brazilian states. Data were collected by means of an individual open interview and analyzed based on Content/Thematic Analysis, obtaining the following categories related to follow-up programs for SEM egresses: creation and implementation, operation, and methodology. The results show that the follow-up programs assume different characteristics across Brazilian States, besides enabling the access of monitored egresses to social policies through a network, based on the institutional incompleteness and the accomplishment of the Individual Plan of Attention. Although these programs represent the continuity of socioeducational measures, a greater investment is required to ensure their continuous offer as a universal policy, establishing a continued service with principles, guidelines, and goals at a national level.
\end{abstract}

Keywords: Socio-educational Measures, Egress, Social Policy, Youth. 


\title{
Caracterización de los Programas de Seguimiento a los Jóvenes Egresados de Medidas Socioeducativas
}

\begin{abstract}
Resumen: Este artículo tiene como objetivo caracterizar los programas de seguimiento a los jóvenes egresados de medida socioeducativa de internación (MSI). En el estudio participaron cuatro miembros de la coordinación de programas de seguimiento a los egresados de MSI de tres estados brasileños. Se utilizó entrevista abierta individual, y para el análisis de los datos se empleó el análisis temático de contenido, del cual se obtuvieron las siguientes categorías: Creación e implementación de los programas de seguimiento a los egresados de MSI; Funcionamiento de los programas de seguimiento a los egresados de MSI; y Metodología de los programas de seguimiento a los egresados de MSI. Los datos analizados mostraron que estos programas tienen características distintas en los estados. Se identificó que facilitan el acceso de los jóvenes acompañados a las políticas sociales, por medio de la realización del trabajo en red con baseen la incompletitud institucional y en la efectividad del Plan Individual de Atención. Se concluye que la existencia de esos programas de seguimiento a los egresados de MSI representa la continuidad de las acciones socioeducativas, pero necesitan mayores inversiones para asegurar la permanencia de la oferta en el formato de una política de carácter universal a partir del establecimiento de un servicio de carácter continuado, con principios, directrices y objetivos a nivel nacional.
\end{abstract}

Palabras clave: Medidas Socioeducativas, Egresados, Juventud, Política Social.

\section{Introdução}

A promulgação do Estatuto da Criança e do Adolescente (ECA), que instaurou a Doutrina da Proteção Integral, trouxe mudanças para o atendimento dos adolescentes autores de atos infracionais. O ECA estabelece seis medidas socioeducativas (MSE): advertência, obrigação de reparar o dano, prestação de serviços à comunidade, liberdade assistida, semiliberdade e internação em estabelecimento educacional, e estabelece que sua aplicação deve considerar a capacidade do adolescente em cumpri-la, as circunstâncias e a gravidade da infração(Lei n. 8.069, 1990). O ECA ainda determina as MSE a serem aplicadas e as garantias processuais do adolescente.

Em relação ao funcionamento das MSE, em 2006, o Conselho Nacional dos Direitos da Criança e do Adolescente (Conanda) estabeleceu os parâmetros arquitetônicos, as diretrizes pedagógicas e os princípios para a execução das medidas socioeducativas por meio de um documento denominado Sistema Nacional de Atendimento Socioeducativo (Sinase). Em 2012, após longa tramitação, foi publicada a Lei Federal n. 12.594 (2012), que passou a regulamentar a execução das MSE em meio fechado e meio aberto em todo o país.
O Sinase tem como objetivos a responsabilização do adolescente pelas consequências lesivas do ato infracional, sempre que possível incentivando a sua reparação; a integração social do adolescente e a garantia de seus direitos individuais e sociais, por meio do cumprimento de seu plano individual de atendimento; e a desaprovação da conduta infracional, efetivando as disposições da sentença como parâmetro máximo de privação de liberdade ou restrição de direitos, observados os limites previstos em lei (Lei n. 12.594, 2012, Art $1^{\circ} \$ 2^{\circ}$ ).

Considerando a especificidade da medida socioeducativa de internação, caracterizada como a MSE mais grave em relação as demais medidas, o ECA estabelece que sua aplicação deve apoiar-se nos princípios de brevidade, excepcionalidade e respeito à condição peculiar de desenvolvimento. Ainda em relação a essas características dessa medida, o ECA e Sinase determinam que as entidades responsáveis por executar as MSE de internação têm a obrigação de desenvolver programas de apoio e acompanhamento aos egressos dessa medida socioeducativa (Lei n. 8.069, 1990).

De acordo com o documento de referência do Sinase (Secretaria Especial dos Direitos Humanos \& Conselho Nacional dos Direitos da Criança e do Adolescente, 2006), que estabelece os parâmetros 
socioeducativos em âmbito nacional, os programas de apoio e acompanhamento aos egressos de MSE devem oferecer atendimento qualificado e estruturado aos jovens, com base na política de socioeducação e seus princípios pedagógicos, auxiliando a transição entre a vivência de privação de liberdade e o retorno a seu território de origem, bem como articulando o acesso às políticas sociais. Apesar dessa obrigatoriedade, poucas entidades têm ofertado programas de apoio e acompanhamento aos egressos de MSE nos estados, de acordo com as informações do Panorama Nacional da Execução das Medidas Socioeducativas de Internação (Conselho Nacional de Justiça, 2012). Como consequência, verifica-se uma escassez de estudos sobre o funcionamento desses programas, considerando sobretudo que o Sinase, apesar de estabelecer a obrigatoriedade dos programas, não trouxe orientações específicas que norteiem a execução do acompanhamento a ser prestado aos egressos de MSE.

Em razão da indefinição de orientações que pudessem guiar a organização dos programas de acompanhamento aos egressos de MSE, verifica-se que eles têm baseado seu funcionamento na Política de Assistência Social. Essa estruturação tem se materializado, principalmente, com base na rede socioassistencial e na proteção social instituída pela Lei Orgânica da Assistência Social (LOAS) (Lei n. 8.742, 1993; Miranda et al., 2014).

Segundo a LOAS, a rede socioassistencial se caracteriza pela oferta de serviços, programas, projetos e benefícios eventuais ou continuados. Os serviços correspondem às ações de caráter continuado, com critérios definidos, usuários específicos, visando à melhoria de vida da população atendida. Os programas referem-se às ações integradas e complementares, com objetivos, período e área de abrangência instituídos para qualificar os serviços socioassistenciais. Os projetos correspondem às ações especificas para determinados grupos, objetivando a melhoria das condições de subsistência, elevar o padrão da qualidade de vida e a organização social. Já os benefícios continuados e eventuais se caracterizam por provimentos prestados aos cidadãos e famílias em situação de vulnerabilidade social (Lei n. 8.742, 1993).

Os programas de acompanhamento aos egressos de MSE executam suas ações com base no princípio da incompletude institucional e do trabalho em rede, ou seja, compreendendo que as instituições socioeducativas não respondem por todas as necessidades dos jovens. Tais demandas devem ser atendidas por meio da articulação entre as políticas de educação, profissionalização e trabalho, saúde, cultura, lazer, esporte, segurança e justiça (Gonçalves \& Guará, 2010; Motti, 2015), a partir da construção e efetivação do Plano Individual de Atendimento (PIA), que deve prever objetivos e metas do acompanhamento (Jimenez, Jesus, Malvasi, \& Salla, 2012).

Ao analisar a situação de jovens egressos de MSE, Barbosa e Resende (2014) discorrem sobre a necessidade da existência de uma política de acompanhamento aos egressos de MSE, cujas ações devem ser realizadas quando os adolescentes ainda estão cumprindo a MSE de internação. Os autores discutem o fato de a medida socioeducativa dever ter como finalidade a saída do socioeducando, ou seja, durante a MSE, devem ser ofertadas as condições necessárias para que o adolescente possa efetivar outras perspectivas de vida e um projeto de futuro após o cumprimento da MSE de internação, considerando a efetivação do PIA a partir das demandas das áreas de educação, saúde e profissionalização. Nesse sentido, a existência de uma política de acompanhamento aos egressos de MSE representaria a continuidade da ação socioeducativa.

Nessa mesma direção, Foppa (2011) identificou que as atividades realizadas por um programa de acompanhamento aos egressos de MSE tinham início durante o cumprimento da medida socioeducativa de internação, em um período anterior ao desligamento do adolescente da unidade. Essa metodologia se caracteriza pelo que a autora denominou de processo de passagem da MSE para o programa de acompanhamento a egresso de MSE. Esse processo de passagem, que se inicia com a apresentação dos objetivos aos adolescentes nas unidades de internação, é realizado por meio de oficinas de sensibilização, seguidas do convite à participação a partir de círculos de compromisso, seguido da assinatura de termos que formalizam a adesão do jovem, de sua família e dos técnicos de referência.

Apesar da utilização dessa estratégia, Foppa (2011) identificou que alguns jovens não compreendiam a finalidade do programa de acompanhamento aos egressos de MSE apenas com a realização de apresentações, posto que o consideravam uma substituição da MSE e que, se não aderissem a ele, poderiam ser punidos ou não receberem a extinção da MSE. Excetuando a dimensão sancionatória, a participação em programas de acompanhamento a egressos 
de MSE tem caráter voluntário, ou seja, os jovens não são obrigados a aderir à proposta, tendo em vista que ela não se caracteriza como medida socioeducativa. Nesse mesmo sentido, a extinção da MSE de internação não pode ser condicionada à adesão do jovem a um programa de acompanhamento a egressos (Chimin Junior et al., 2008).

A existência de programas de apoio e acompanhamento, tal como estabelece o Sinase (Secretaria Especial dos Direitos Humanos \& Conselho Nacional dos Direitos da Criança e do Adolescente, 2006), se justifica em razão da dificuldade dos jovens em acessar os direitos sociais após o cumprimento da medida socioeducativa de internação. De acordo com Ferraz (2013), grande parte das instituições que compõem o Sistema de Garantia de Direitos (SGD) apresentam resistências em receber esses jovens, agindo com preconceito e muitas vezes omitindo a existência de vagas em escolas, em unidades de saúde e em políticas de moradia, profissionalização e emprego. Além desses fatores, Gonçalves (2017) discute que extensos períodos de internação trazem implicações subjetivas aos jovens que vivenciam dificuldades em retomar $o$ gerenciamento e a autonomia da própria vida. Nesse sentido, a existência de programas de acompanhamento ao egresso de MSE pode facilitar o acesso e a permanência dos jovens nessas outras políticas.

Apesar de exercer essa função, a implantação de programas de acompanhamento aos egressos de MSE enfrenta dificuldades em sua consolidação. Segundo Nardi e Dell'Aglio, (2014), existem poucos estados que ofertam esse acompanhamento, de forma que os jovens que saem das unidades de MSE de internação vivenciam dificuldades em seu retorno ao território de origem ou continuam buscando apoio das equipes técnicas das unidades de MSE (Prado, 2014). Alguns autores (Chimin Junior et al., 2008; Nardi \& Dell'Aglio, 2014) apontam a necessidade da existência obrigatória de uma política de acompanhamento aos jovens egressos de MSE, ofertadas pelos órgãos gestores, de caráter permanente e disponibilizada para todos os jovens egressos, de modo a oferecer acompanhamento aos jovens e seus familiares e a promover articulações com as políticas sociais.

Embora a existência desses programas se apresente como necessária, sua manutenção não tem sido garantida pelo Estado. De acordo com Behring e Boschetti (2006), a criação das políticas sociais é permeada por conflitos de interesses entre as classes sociais, caracterizadas por relações complexas e contraditórias. Neste artigo, parte-se da concepção de política social como uma forma de intervenção do Estado na questão social, questão que é compreendida como o conjunto de problemas políticos, econômicos e sociais resultantes da relação entre o capital e a classe trabalhadora. A política social converte-se em várias políticas sociais, o que reduz os investimentos nessa área e torna sua execução fragmentada, parcializada e focalizada em problemas específicos, além de as caracterizar pela instabilidade e implantação tardia da oferta, longe de objetivarem a modificação das estruturas que produzem e reforçam as expressões da questão social (Behring \& Boschetti, 2006; Netto, 2011). Além disso, deve-se considerar que, no contexto do neoliberalismo, com a redução dos investimentos, as demandas são classificadas por prioridades, o que gera disputas na escolha e na criação das políticas (Agum, Riscado, \& Menezes, 2015) ou formação de diversas alianças, que transferem a responsabilidade da oferta de serviços do Estado para agências privadas ou mesmo para a sociedade civil (Netto, 2011).

Apesar da obrigatoriedade determinada pelo ECA e pelo Sinase, as poucas experiências de programas de apoio e acompanhamento aos egressos de MSE têm se efetivado de formas diferenciadas nos estados brasileiros. Segundo Ferrão, Santos e Dias (2016) e Araújo (2017), os programas existentes têm se fundamentado em perspectivas distintas. Segundo Araújo (2017), alguns programas de acompanhamento aos egressos de MSE pautam-se na perspectiva da ressocialização, ou seja, compreendem que o jovem que praticou um ato infracional, sofreu uma falha em seu processo de socialização e, após ser alvo da intervenção institucional ao cumprir uma medida socioeducativa, estaria apto a reintegrar-se à sociedade e não praticar outros atos infracionais. Como consequência dessa perspectiva, o objetivo do programa de acompanhamento aos egressos de MSE estaria na prevenção e na diminuição dos índices de reincidência infracional (Marinho \& Galinkin, 2017).

Outros autores identificaram a existência de outras perspectivas que podem subsidiar as ações e os objetivos desses programas, de forma exclusiva ou simultânea à concepção anterior. Segundo Ferrão et al. (2016), alguns programas de acompanhamento aos egressos de MSE têm subsidiado suas ações a partir da Justiça Restaurativa (JR) e da utilização de práticas restaurativas. Dentre elas, a principal é a prática 
de círculos de compromisso, realizada na transição entre a extinção da MSE de internação e a adesão ao programa de acompanhamento aos egressos de MSE. Além dessas práticas, foi identificada por Amorim (2018) a presença dos princípios da JR, por meio da postura restaurativa das equipes das instituições, cujo objetivo é evitar julgamentos e preconceitos e combater a cultura punitiva ainda tão marcante nas unidades socioeducativas. Outra perspectiva utilizada na socioeducação é a dos Grupos Operativos (GO) de Pichon Rivière, que se baseia na realização de atividades em grupos, cujos princípios são as possibilidades de aprendizagem e de leitura crítica da realidade, além da construção de vínculos com equipe técnica, socioeducandos e familiares, estratégia que possibilita a maior escuta e diálogo e se distancia de posturas punitivas (Mota, 2016).

Consideramos que os programas de acompanhamento aos egressos de MSE devem pautar suas ações no desenvolvimento da autonomia dos jovens acompanhados. A concepção de autonomia aqui compreendida é estabelecida a partir da psicologia histórico-cultural, que compreende o desenvolvimento humano não de modo universal e natural, mas como algo que é delimitado por condições históricas concretas e que possui uma relação de dependência com a atividade social (Pasqualini, 2016).

Para a psicologia histórico-cultural, a autonomia está vinculada ao processo de busca da realização pessoal, que pode estar relacionada com atividade de formação profissional ou de trabalho e com o estabelecimento de relações sociais. Desse modo, a autonomia não é apenas o resultado do aspecto cronológico, mas é compreendida como "uma realização a ser conquistada" diante das condições concretas que se apresentem aos jovens (Abrantes \& Bulhões, 2016, p. 247). Está ligada ao estabelecimento de um projeto de vida e de processos decisórios que implicam na construção de maior grau de autonomia dos sujeitos e que dependem do maior ou menor acesso aos bens culturais e sociais. Desse modo, a autonomia proporcionada pelos programas de acompanhamento aos egressos de MSE deve estar diretamente relacionada à qualidade das mediações realizadas, que promovem o acesso aos direitos sociais e a efetivação do projeto de vida.

Considerando o exposto, este artigo tem como objetivo caracterizar os programas de acompanhamento aos jovens egressos de medida socioeducativa de internação. Parte-se do pressuposto de que os programas de acompanhamento aos egressos de
MSE podem qualificar o trabalho socioeducativo, na medida em que exercem a função de articular as políticas sociais, facilitam o acesso dos jovens aos direitos sociais e não possuem uma natureza sancionatória. No entanto, essa qualificação do trabalho socioeducativo necessita da existência de uma política permanente de acompanhamento a egressos de MSE, de caráter universal, com princípios, diretrizes e objetivos estabelecidos em âmbito nacional.

\section{Método}

A pesquisa foi realizada em três estados brasileiros, a partir de um levantamento inicial no qual se identificou quais estados ofertavam os programas. Após a identificação, foi realizado o contato com os programas existentes nos estados da Bahia, da Paraíba e do Rio Grande do Sul, que aceitaram a participação no estudo e o agendamento da pesquisa de campo. Para a coleta de informações, foram utilizadas entrevistas abertas individuais com quatro membros de coordenação nos três programas de acompanhamento aos jovens egressos de medidas socioeducativas, as quais abordaram temas norteadores acerca da caracterização dos três programas visitados, como a identificação dos princípios e diretrizes que norteiam os programas de acompanhamento aos egressos de MSE, os objetivos do acompanhamento aos jovens e as ações oferecidas nesses programas.

O presente estudo foi realizado com apoio da Coordenação de Aperfeiçoamento de Pessoal de Nível Superior - Brasil (Bolsista Capes/Brasil) - Código de Financiamento 001. Foram cumpridos todos os preceitos éticos pertinentes à pesquisa com seres humanos, conforme a Resolução no 510/2016 do Conselho Nacional de Saúde, obtendo-se o Certificado de Apresentação para Apreciação Ética (CAAE) $n^{\circ}$ 87110418.9.0000.5188. As entrevistas foram gravadas com anuência das instituições e assinatura do Termo de Consentimento Livre e Esclarecido (TCLE) pelos participantes, e posteriormente transcritas e analisadas a partir da Análise Temática de Conteúdo (Minayo, 2014). Inicialmente, empreendeu-se uma leitura flutuante de todo conteúdo transcrito, a fim de obter uma visão geral dos dados. Após essa etapa, realizou-se a exploração do material que corresponde à classificação dos núcleos textuais, com a utilização de categorias temáticas a partir das partes mais representativas do texto, que foram organizadas posteriormente em classes temáticas, discutidas 
com base no referencial teórico-metodológico adotado. As classes temáticas construídas na análise foram: criação e implementação dos programas de acompanhamento aos egressos de MSE; funcionamento dos programas de acompanhamento aos egressos de MSE; e metodologia dos programas de acompanhamento aos egressos de MSE.

\section{Resultados e discussão}

\section{Criação e implementação dos programas de acompanhamento aos egressos de MSE}

Nesta classe temática, foram identificadas as categorias referentes a criação e implementação dos programas de acompanhamento aos egressos de MSE nos diferentes estados visitados. As categorias identificadas foram: "História da criação dos programas", "Abrangência”, "Composição da equipe", "Legislação", “Tipo de oferta” e "Interrupções da oferta". Na categoria "História da criação dos programas", os coordenadores relataram o percurso de criação dos programas de acompanhamento aos jovens egressos de MSE em cada estado, revelando as trajetórias diferenciadas de criação e implementação, as mudanças ocorridas desde o início da implantação e como esses programas têm se caracterizado atualmente, como demonstrado na fala de um dos coordenadores de um dos programas:

A lei nasceu em 2009 e eram poucas vagas né, eram 180 vagas distribuídas inicialmente entre [alguns municípios].. Com a lei do novo marco regulatório que possibilitou as OSC [Organizações da Sociedade Civil] apresentar manifestação de interesse público ..., a [instituição executora do programa de acompanhamento ao egresso de MSE] chegou e disse: "além disso tudo que eles fazem, eu ainda coloco um viés profissionalizante de encaminhamento ao mundo do trabalho e ao invés de 180 vagas, eu dou 1100 vagas para todo o Estado" (Coordenação 1).

As origens dos programas de acompanhamento ao egresso de MSE revelam motivações diferenciadas entre os estados brasileiros. Dentre elas, figura a imposição do sistema de justiça para a criação desses programas, em oposição ao o reconhecimento da necessidade de os jovens receberem esse acompanhamento e ao cumprimento pelo Sinase da oferta desses programas vinculados a todas as entidades de meio fechado no Brasil, como pode ser observado na fala: "Então o serviço de egresso foi uma exigência do Ministério Público né, que sempre tá em consonância, Ministério Público,... , que fica lá o promotor de justiça né, a rede, então foi uma exigência pra criar o serviço de egresso" (Coordenação 4).

Na categoria "Abrangência", foi identificado que, nos estados visitados, os programas de acompanhamentos aos egressos de MSE dispõem de uma cobertura estadual. São ações vinculadas às instituições executoras da medida de meio fechado, de âmbito estadual, que, para garantir o alcance e amplitude do acompanhamento, subdividem-se em equipes localizadas nas capitais dos estados e outras distribuídas em regiões metropolitanas. Apesar dessa divisão, verifica-se nos relatos que a quantidade de equipes $\mathrm{e}$ profissionais é insuficiente diante da demanda distribuída pelos demais municípios, o que reflete na forma como o acompanhamento é prestado, que passa a ser realizado não mais com acompanhamento direto, mas sim com o monitoramento das outras políticas sociais, principalmente as de assistência social.

A [equipe da cidade polo] atende diretamente a unidade de internação em [cidade polo]. E [equipe da capital] fica com as unidades daqui da [capital] e região metropolitana, que pega [demais municipios]. Termina que a gente tem uma sobrecarga muito grande por isso e aí assim, os meninos que vão pra o interior a gente termina fazendo esse monitoramento via e-mail, via telefone, porque não tem como ter atendimento presencial, então a gente pede que a rede socioassistencial preste esse atendimento (Coordenação 3).

$\mathrm{Na}$ categoria "Composição da equipe", identificou-se que os programas de acompanhamento ao egresso de MSE possuem, em suas equipes técnicas, profissionais de formação variadas, de modo que algumas possuem equipes técnicas de referência, baseadas na política do SUAS: "Na equipe eu tenho um psicólogo, três assistentes sociais, uma pedagoga, uma analista técnica, seis técnicos administrativos e a equipe de limpeza, uma copeira e segurança patrimonial' (Coordenação 3), enquanto outras contam apenas com uma equipe mínima, sem variedade na 
formação de profissionais, o que se mostra insuficiente de acordo com a avaliação realizada pela coordenação do programa.

Na categoria "Legislação", os coordenadores relataram a importância da existência de leis específicas para subsidiar e financiar os programas de acompanhamento aos egressos de MSE. A existência de legislações próprias também exerce a função de garantir a permanência da oferta da política e da metodologia utilizada, mesmo com mudanças entre os governos eleitos. Destaca-se que alguns estados ainda não possuem essa legislação específica e estão em fase de criação de leis, enquanto outros estão atualizando suas normativas, estabelecendo mudanças de acordo com as dificuldades vivenciadas durante sua execução, conforme pode ser observado na seguinte fala:

Um decreto é aqui nosso, que tem o grupo gestor, então que a gente... que ele, é lá de 2009, então a gente tem que atualizar ele pras demandas de agora, pra deixar bem claro assim, pra que o programa, entre novos governantes ou não, eles, todo mundo consiga interpretar ele bem (Coordenação 1).

Na categoria "Tipo de oferta", foram relatadas pelos coordenadores diferenças quanto à tipificação dos programas de acompanhamento aos egressos de MSE, ou seja, em alguns estados, a política é ofertada em forma de programa; em outros, com a tipificação de serviço. Essa diferença revela que os programas de acompanhamento ao egresso de MSE não têm se baseado como uma política universal apoiada no Sistema Nacional de Atendimento Socioeducativo. Embora demonstrem a autonomia dos estados na efetivação de suas propostas, mostra, por outro lado, uma fragilização do acompanhamento aos jovens e da permanência da oferta, marcada por flutuações em sua manutenção, o que pode se refletir em objetivos e formas divergentes de prestar o acompanhamento. As falas a seguir demonstram as diferenças existentes em alguns estados visitados:

O serviço é delegar, descentralizar, não fica só na gente, a gente não vai atender, a gente tem que amarrar isso na unidade pra que ele seja atendido no CRAS, no CREAS, seja atendido no Sine, né, na escola (Coordenação 4).

$\mathrm{Na}$ categoria "Interrupções da oferta", identificou-se que os programas de acompanhamento ao egresso de MSE passam por flutuações em sua execução, na medida em que não contam com a garantia de subsídios para uma oferta permanente. Essas interrupções podem trazer consequências para os jovens acompanhados.

Ah, houve bastante, porque antigamente... funcionava como convênio e o convênio ele é muito... todos os anos tem que prorrogar ele, tu tem que fazer novo chamamento público e... então a gente vivia assim, começava com um... havia aquela interrupção, havia interrupção dos meninos que já estavam lá, já tinham feito vínculo com os técnicos, e depois tinham que se adaptar a outro (Coordenação 1).

Pode-se analisar, em relação à classe temática "Criação e implementação dos programas de acompanhamento aos egressos de MSE", que estes têm se baseado na tipificação proposta na Lei Orgânica da Assistência Social, especificamente na definição dos serviços e programas socioassistenciais (Lei n. 8.742, 1993; Miranda et al., 2014). Destaca-se que o documento guia do Sinase (Secretaria Especial dos Direitos Humanos \& Conselho Nacional dos Direitos da Criança e do Adolescente, 2006) faz menção à criação e à manutenção de programas, ou seja, refere-se a um tipo de ação complementar, com período delimitado para sua execução. Alguns estados apresentam avanços, na medida em que consideram o acompanhamento a egressos de MSE como um serviço socioassistencial, por este ser definido, na política de assistência social, como uma ação de caráter continuado, enquanto os programas envolvem ações complementares (Miranda et al, 2014). Nesse sentido, o estabelecimento de uma política de acompanhamento aos egressos de MSE, definida no formato de um serviço, poderia minimizar as interrupções da oferta dos programas e as consequências decorrentes da descontinuidade da prestação para os jovens egressos de MSE.

A tipificação da oferta dos programas de acompanhamento aos egressos de MSE, embora seja obrigatória segundo as determinações dos marcos legais, não tem se apresentado como uma política nacional e universal tal como o Sinase. Consequentemente, observa-se, nesses programas, trajetórias e motivações diferentes em seu processo de implementação, que não asseguram a permanência de sua oferta (Miranda et al., 2014). Apesar do caráter descontinuado do acompanhamento 
a egressos de MSE no formato de programas, compreende-se que sua existência representa uma possibilidade de acesso às políticas sociais na tentativa de minimizar a situação de vulnerabilidade dos jovens após cumprimento da MSE (Prado, 2014), logo, a descontinuidade da oferta desse tipo de ação pode trazer implicações para o regresso desses jovens a seus territórios de origem (Ferraz, 2013; Gonçalves, 2017).

Ao retornarem a seus bairros, os egressos de MSE apresentam diversas necessidades, ao mesmo tempo em que não recebem apoio das políticas sociais, o que justifica a existência de programas de acompanhamento aos egressos de MSE, cuja função é articular as políticas sociais que têm desenvolvido ações fragmentadas e pontuais (Chimin Junior et al., 2008; Nardi \& Dell'Aglio, 2014). Se o fato de os programas de acompanhamento aos egressos não se constituírem enquanto uma política permanente traz consequências para o acesso às políticas sociais, muito mais agravada torna-se a função desses programas, por não conseguirem possibilitar a conquista da autonomia. Isso porque sua interrupção não proporciona o acesso aos bens culturais de forma contínua, nem a construção de projetos de vida que impulsionem os processos decisórios dos jovens e sua progressiva realização pessoal (Abrantes \& Bulhões, 2016).

A análise sobre a Criação e implementação de programas de acompanhamento aos egressos de MSE não pode se deslocar da compreensão do cenário das políticas sociais no capitalismo, permeado por conflitos de interesses e tensões que marcam sua oferta e manutenção, e nem do entendimento de como as políticas sociais são executadas no neoliberalismo, marcado pela redução dos investimentos na área social, o que fragmenta e parcializa as políticas, que passam a focar apenas em problemas específicos que não objetivam a transformação das estruturas produtoras da questão social (Behring \& Boschetti, 2006; Netto, 2011).

Identificou-se que a implantação dos programas de acompanhamento aos egressos nos estados ocorre vinculada à política de socioeducação, que enfrenta dificuldades em sua efetivação. Esses obstáculos decorrentes da falta de investimentos e da precarização das políticas sociais, fazem com que a política de socioeducação enfrente desafios de implementação que se caracterizam pelo número reduzido de profissionais diante da alta demanda, em descumprimento à proporção entre o tamanho da equipe técnica e o público-alvo; pela falta de estrutura para garantir o atendimento e a amplitude da cobertura; pela descontinuidade no modelo de gestão que varia de acordo com a mudança de governos e não se institucionaliza como uma política permanente de Estado; e pela discrepância entre o estabelecido na legislação e a materialização da política social nos equipamentos e ações (Miranda et al., 2014).

Outra questão que apresenta repercussões nos programas de acompanhamento aos egressos de MSE é a diferença na execução da política de socioeducação entre os municípios do mesmo Estado, tendo em vista que nas capitais as ações dos programas estão mais estruturadas e possuem maiores articulações com as demais políticas, enquanto nas demais cidades essa composição está mais fragilizada. A discrepância da oferta de programas também pode ser observada entre os diferentes Estados, com avanços observados em alguns e a criação tardia em outros, o que representa obstáculos à consolidação de uma política de socioeducação de caráter universal (Jimenez et al., 2012).

\section{Funcionamento dos programas de acompanhamento aos egressos de MSE}

A classe temática "Funcionamento dos programas de acompanhamento aos egressos de MSE" diz respeito à organização da oferta. Foram identificadas as categorias "Concepções que norteiam o acompanhamento", "Objetivos”, "Critérios de participação nos programas de acompanhamento a egressos de MSE" e "Metas". Na categoria "Concepções que norteiam o acompanhamento", identificou-se que os coordenadores relatam tanto a existência de uma perspectiva teórica utilizada para subsidiar todas as ações e dimensões da oferta, a exemplo da utilização da Justiça Restaurativa e da perspectiva de Grupos Operativos de Pichon, como a presença de perspectivas teóricas que fizeram parte de sua formação profissional influenciando a organização e o funcionamento dos programas de acompanhamento aos egresso de MSE, como a pedagogia de Paulo Freire e de Antônio Carlos Gomes da Costa, a psicologia social e o compromisso ético-político do serviço social, conforme as falas a seguir:

É dentro daquela coisa da Justiça Restaurativa inclusive, é o que se basearam eu não sei, mas é uma política pra redução da criminalidade né, que não volte a reincidir, que não vá pro sistema adulto né, é toda essa coisa assim entendeu, dentro de um critério de ressocialização (Coordenação 1). 
Quanto aos “Objetivos" dos programas de acompanhamento ao egresso de MSE, identificaram-se finalidades distintas. Alguns programas estabelecem como objetivos principais a ressocialização e a prevenção da reincidência do ato infracional, enquanto outros estados pautam seus objetivos na perspectiva dos jovens acompanhados, com a finalidade de os auxiliarem a construir outras perspectivas de vida, distanciadas da prática de atos infracionais. Nessa ótica, as possibilidades oferecidas visam promover a autonomia dos jovens e não funcionar como uma política de caráter tutelar. As falas a seguir ilustram essas diferenças: "O objetivo que não tenha mais a reincidência do ato infracional" (Coordenação 4).

Construção de autonomia responsável seria o objetivo geral né? Que a gente permita a esse jovem, possibilidades de construir a sua autonomia de forma mais responsável, porque quando a gente para pra pensar que, quase sempre eles vão estar agora, maiores por si só (Coordenação 3).

Sobre os "Critérios de participação nos programas de acompanhamento a egressos de MSE", identificaram-se diferentes critérios para cada fase do acompanhamento, que se referem a inclusão, permanência, realização de encaminhamentos e desligamento dos programas. Os três estados mencionaram que o principal critério é a voluntariedade do jovem na adesão, ou seja, não há imposição da participação. Em relação ao desligamento, observaram-se os critérios da idade máxima permitida, da participação ativa do jovem nos programas e mesmo a própria decisão do jovem de se manter acompanhado ou se desligar.

Primeiro, pra ser inserido no programa de egressos tem que ser algo que parta do egresso né? ... desligamento não teve não... a gente sempre faz as reuniões pra discussão de caso, estudo de caso, alguns a gente percebe que já evoluíram bastante né? ainda assim a gente procura deixar que eles sinalizem né? se antes dos dois anos a gente só desliga se ele sinalizar: "oh, já tô de boa e tal..., já tô tranquilo, tô bem, tô trabalhando e tal, então eu acho que por enquanto eu posso me desligar" (Coordenação 3).

Outros critérios divergentes dizem respeito à definição de quem é o jovem egresso acompanhado. Alguns estados acompanham jovens que cumpriram MSE de internação e que, na audiência, receberam a substituição da MSE de meio fechado por uma medida de meio aberto, seja Liberdade Assistida (LA), seja PSC. Outros estados, porém, definem como egresso aquele jovem que cumpriu a MSE de internação e recebeu a extinção da medida socioeducativa na audiência, ou seja, é voltada para aquele jovem que não esteja cumprindo nenhuma medida socioeducativa. Outra questão relacionada aos critérios diz respeito ao tempo de acompanhamento, de modo que alguns programas determinam o tempo mínimo de 6 meses e outros garantem o acompanhamento mínimo de um ano, e ambos podem ser prorrogadas por igual período, a depender das necessidades dos jovens e do que foi estabelecido em seus planos individuais de atendimento (PIA).

. . que o serviço de egresso, ele vai acompanhar os adolescentes que estão extintos de medida socioeducativa, não LA nem PSC, extintos de fato. ... e o tempo de acompanhamento que a gente vai ter que assessorar e acompanhar são 6 meses (Coordenação 4).

Na categoria "Metas", verificou-se que elas são diferentes de acordo com o status em que cada programa se encontra. Enquanto em alguns estados verifica-se o desenvolvimento de metas para o acompanhamento, na tentativa de ampliar seu alcance para um número maior de jovens e estabelecer maiores articulações com as políticas sociais, atendendo de modo mais eficaz as demandas dos jovens, outros programas em fase de implementação têm metas centradas em consolidar inicialmente a oferta no estado, para depois direcionar as metas voltadas aos jovens. A fala de um dos coordenadores ilustra a elaboração das metas:

No plano de trabalho existe as metas, da redução, tu vai ver cada etapa tem uma meta, reduzir o número, a redução do número de retornos pra [instituição de MSE de internação] é a meta número 1; diminuir a evasão escolar; incluir o jovem e sua família né, os vínculos familiares também; então todas essas coisas, tudo isso tem metas, 100\%; 90\% depende... O que a gente cobra muito do nosso parceiro é tentar levar o maior número de meninos... a entrar no nosso programa, isso a gente é cobrado muito, nós temos hoje assim 90; 95\%... (Coordenação 1).

No que diz respeito ao "Funcionamento dos programas de acompanhamento aos egressos", identificou-se que eles não compartilham princípios e diretrizes apoiados em uma política nacional, 
tal como a política de socioeducação, apresentando unicamente objetivos, metas e critérios particulares em cada estado, sem um projeto político-pedagógico sobre seu funcionamento. Verificou-se que alguns programas estão apoiados na perspectiva da ressocialização e prevenção da reincidência, ou seja, pautados na ideia de um ajustamento daqueles sujeitos que em determinado momento da vida experienciaram falhas em seu processo de socialização e que, após ser alvo de intervenções, poderiam retornar ao convívio social. Essa concepção tem permeado as ações dos sistemas socioeducativo e prisional, decorrentes da lógica das denominadas ilusões "re", ressocialização, reeducação e reabilitação, que se apoiam na ideia de uma suposta recuperação (Araújo, 2017), porém, sem considerar as características da sociedade e os efeitos da privação de liberdade. Segundo essa perspectiva, ao promover a ressocialização, poder-se-ia minimizar os índices de reincidência infracional (Marinho \& Galinkin, 2017).

Verificou-se também que essa não é a única concepção que norteia os programas de acompanhamento aos egressos de MSE. Há também a perspectiva da promoção da autonomia dos jovens acompanhados. Consideramos que o desenvolvimento da autonomia na sociedade capitalista se apresenta de formas distintas para as diferentes classes sociais, de forma que para a juventude da classe trabalhadora, essa autonomia tem se relacionado com o ingresso precoce no mercado de trabalho, enquanto os demais jovens podem dedicar-se a um tempo maior de estudos e de formação profissional (Abrantes \& Bulhões, 2016). Para os jovens que cumpriram MSE, em muitos casos, essa inserção precoce no trabalho ocorreu por meio do tráfico de drogas, o que culmina na responsabilização deles, apesar de realizarem atividades consideradas como Piores Formas de Trabalho Infantil e não receberem, por isso, ações protetivas.

As divergências existentes entre as características dos programas nos estados repercutem em concepções teóricas diferentes. Essas, por sua vez, nem sempre estão definidas nos marcos legais próprios, na medida em que são apontadas a partir das perspectivas dos gestores, dos coordenadores ou da formação teórico-metodológica de cada profissional que faz parte da equipe técnica de referência. Em um dos programas, observou-se que a teoria e a prática metodológica são fundamentadas pela Justiça Restaurativa, que é utilizada em todas as etapas do acompanhamento, desde o cumprimento da MSEI até o acompanhamento no programa de egressos, representando uma perspectiva de gestão socioeducativa (Amorim, 2018). A Justiça Restaurativa, materializada por meio da postura restaurativa das equipes das instituições socioeducativas, objetivando a mudança da cultura nessas unidades (Amorim, 2018). Além disso, há a utilização de práticas restaurativas, principalmente dos círculos de compromisso, utilizados ainda durante o cumprimento da MSE de internação, com a participação do jovem, seus familiares e técnicos de referência, no qual são realizados acordos entre as partes, objetivando o momento após a extinção da MSE de internação (Ferrão et al., 2016; Foppa, 2011).

As outras perspectivas teóricas mencionadas pelos membros das equipes dos programas não apresentavam uma concepção teórica norteadora da gestão socioeducativa de modo formalizado nos marcos legais próprios, mas eram utilizadas enquanto teoria e metodologia por uma equipe ou por alguns profissionais. Dentre elas, foi mencionada a perspectiva de grupos operativos de Pichon Riviere, que, nos programas de acompanhamento a egressos, são utilizados para aproximar a relação entre socioeducadores, equipe técnica e socioeducandos, a partir dos seguintes princípios: a execução da tarefa como um objetivo comum à execução das atividades e à formação de vínculos entre jovens e equipe; e o estabelecimento de uma relação de pertencimento dos jovens ao programa de acompanhamento a egressos de MSE, por meio da criação de relações de confiança fundamentais no processo de construção dos projetos de vida (Mota, 2016).

As concepções que subsidiam os programas incidem diretamente nos objetivos, critérios e metas propostos e na própria definição do que é um egresso de MSE. Enquanto os programas que se baseiam na ressocialização elegem como prioridade a prevenção da reincidência, os programas que se baseiam na autonomia a têm considerado como um processo a ser trilhado a partir do que lhe é ofertado (Abrantes \& Bulhões, 2016), realizado por meio de ações e instrumentos, a exemplo da efetivação do Plano Individual de Atendimento, priorizando as necessidades e os desejos apontados pelos jovens acompanhados.

As diferenças nas características dos programas se expressam nas metas, relacionadas ao status em que cada um deles se encontra. Enquanto os programas que já estão mais consolidados elegem como meta a ampliação do número de jovens acompanhados, o programa que está na fase de implementação 
tem como primeira meta o estabelecimento do serviço no estado, mobilizando os representantes do Sistema de Garantia de Direitos em relação à importância desse serviço e à necessidade de o inserir como uma demanda reconhecida na agenda de políticas. Os impasses à criação e à consolidação dos programas são decorrentes dos desafios da implantação das políticas sociais no capitalismo, que são permeadas por interesses contraditórios na disputa por recursos financeiros que possam manter determinada política (Agum et al., 2015; Brancaleon, Yamanaka, Castro, Cuoghi, \& Paschoalotto, 2015; Rua, 2009).

\section{Metodologia dos programas de acompanhamento aos egressos de MSE}

Na classe temática "Metodologia dos programas de acompanhamento aos egressos de MSE", foram identificadas as seguintes categorias: "Fluxo do acompanhamento", "Instrumentos utilizados no acompanhamento" e "Articulações com as políticas sociais".

Sobre o "Fluxo do acompanhamento", os programas de acompanhamento aos egressos de MSE utilizam uma metodologia que se inicia ainda durante o cumprimento da MSE de internação, quando a oferta é apresentada aos jovens, seja no formato de oficinas, seja de apresentações, seguida de um convite para sua participação e adesão, que ocorre a partir da extinção ou substituição da MSE de internação. A relevância desse convite acontecer ainda durante o tempo de cumprimento de MSE justifica-se tanto para manter o contato com os jovens, como para poder lhes explicar de maneira mais detalhada a proposta do acompanhamento, seus eixos de ação e o critério de voluntariedade.

A gente faz um trabalho ainda dentro da [instituição executora das MSE de meio fechado]. Eaí entãoé feita essa oficina de sensibilização, aí tá, marca uma audiência e o que que faz? . . o círculo de compromisso que é aquele rito de passagem... pra chegar e fazer um plano individual, um PIA egresso dele... aí ele tem a audiência... E aí depois ele comparece [no programa de acompanhamento ao egresso de MSE], ele tem um acolhimento né, ele vai ter o seu técnico de referência (Coordenação 1).

Evidencia-se nos estados visitados a articulação entre as unidades de MSE de internação e os programas de acompanhamento aos egressos em todas as etapas do fluxo de acompanhamento, considerando a necessidade de as instituições de internação executarem um trabalho de previsão das extinções da MSE e de informação aos programas de acompanhamento. Destaca-se ainda que, no fluxo estabelecido entre as entidades, há forte influência do sistema de justiça. Apesar de os programas analisados apresentarem o critério de voluntariedade e de não condicionarem formalmente a extinção da MSE de internação à adesão ao programa de acompanhamento aos egressos, essa condicionalidade emerge de forma subjetiva no momento da audiência, tanto para os jovens que aguardam a liberdade, como para os profissionais que passam a sinalizar em suas avaliações a existência de um programa de acompanhamento de egressos de MSE, e para as autoridades judiciárias que passam a recomendar a adesão dos jovens após a saída das unidades de internação.

Na categoria "Instrumentos utilizados no acompanhamento", identificou-se que os programas de acompanhamento aos egressos de MSE possuem os seguintes instrumentais: Planos Individuais de Atendimento (PIA), que recebem nomenclaturas próprias em cada estado e possuem uma estrutura semelhante aos PIA utilizados durante o cumprimento da MSE, organizados a partir dos eixos pedagógicos do Sinase; protocolos de fluxos de acompanhamento e encaminhamento para as demais políticas sociais; prontuários cadastrais e de evolução dos acompanhamentos relatórios; e cartazes informativos sobre os programas de acompanhamento a egressos de MSE.

Aí lá no PIA, o que que tu quer fazer? Eu vou estudar. Qual é o ano que tu vai estudar tu tem demandas? É uma complementação. Que que tu quer fazer? Ah, o [instituição executora do programa de acompanhamento ao egresso de MSE] tem tal, tal curso, tal oficinas pra ti fazer, tu queres fazer, o que tu te identifica mais? (Coordenação 1).

Na categoria temática "Articulações com as políticas sociais", foram identificadas duas subcategorias: "Encaminhamentos para as políticas sociais" e "Relações com o sistema de justiça". Em relação aos encaminhamentos, identificou-se o estabelecimento de articulações com as políticas de educação, profissionalização e trabalho, cultura, lazer, esporte e saúde e demais programas e projetos, com base nas necessidades apontadas pelos jovens que são pactuadas nos PIAS, e realiza-se o trabalho em rede para que essas políticas recebam os encaminhamentos: 
É só questão de trabalhar essa rede, entendeu, se comunicar, sensibilizar...o grupo gestor é formado por cultura, educação, saúde, [instituição executora do programa de acompanhamento ao egresso de MSE], [instituição executora das MSE de meio fechado], secretaria (Coordenação 2).

Os coordenadores entrevistados mencionaram a existência de dificuldades nas articulações com demais políticas sociais de educação, profissionalização etc., em razão do estigma em relação aos jovens que cumpriram MSE. Para minimizar tais dificuldades, os coordenadores relataram utilizar estratégias como a omissão de que os jovens cumpriram uma MSE, excluindo informações sobre histórico escolar ou origem da instituição que realizou o encaminhamento, assim como acionam instâncias superiores de defesa, como o Ministério Público, para garantir, por exemplo, matrículas na rede pública de ensino. Outras estratégias utilizadas correspondem ao trabalho em rede, por meio de visitas institucionais, nas quais os programas de acompanhamento aos egressos de MSE são apresentados e são divulgados os impactos do acompanhamento e as contribuições para os jovens.

Então assim, a gente às vezes tem que criar estratégias, primeiro seduzir quem tá do outro lado né? é pra poder criar um campo de, de abertura, de facilitação e em alguns momentos a gente ser mais incisivo: "oh, se você não quiser matricular, eu vou ter que pedir ao Ministério Público que autue a escola, porque eu não tenho condição de privar o jovem de estudar e essa é a escola mais próxima da casa dele. Saúde é uma coisa mais flexível porque a gente não teve nenhuma situação ainda de resistência ao atendimento (Coordenação 3).

Já na categoria "Relações com o sistema de justiça", foi identificada uma forte submissão ao poder judiciário. Contraditoriamente, ao mesmo tempo em que os programas determinam a voluntariedade do jovem na participação, percebe-se que, nos estados, a decisão da extinção da MSE de internação, realizada pelo judiciário, está condicionada à adesão do jovem ao programa de acompanhamento ao egresso de MSE. Ainda sobre essa relação, considerando a abrangência estadual do programa de acompanhamentos aos egressos de MSE, os coordenadores relataram divergências na compreensão das autoridades judiciárias nas diferentes comarcas. Enquanto alguns juízes baseavam suas decisões no trabalho socioeducativo realizado nas unidades de MSE de internação e nos programas de acompanhamento aos egressos de MSE, outros juízes desconsideram esse trabalho e baseiam a extinção apenas no critério do tempo máximo permitido para a aplicação da medida socioeducativa, que, de acordo com o ECA, não pode exceder a três anos.

Tranquila, tranquila sim, eles, o judiciário é o grande incentivador né, isso pra o judiciário é muito bom né, porque o juiz tem uma tranquilidade maior quando solta.... A gente tem que sensibilizar alguns lugares porque os juízes têm aquilo assim: vou trancafiar três anos. . . Isso também são coisas que nós estamos tentando fazer, ir lá e marcar uma conversa, tentar sensibilizar, mostrar o programa ... nós temos muito isso, do judiciário ser muito diferente, do MP, da própria cidade. (Coordenação 1).

Em relação à "Metodologia dos programas de acompanhamento aos egressos de MSE", verificou-se que elas exercem uma função principal de articulação com as demais políticas sociais, principalmente de educação, profissionalização e inserção no mercado de trabalho e de assistência social, seguidas das políticas de lazer, esporte cultura e saúde (Prado, 2014). Tais políticas sociais são acionadas de acordo com as demandas e desejos dos jovens acompanhados, a partir da elaboração do Plano Individual de Atendimento, com a pactuação de objetivos e metas que auxiliem os jovens a efetivar os projetos de vida. Identificou-se que a relação com sistema de justiça é marcada por uma dependência, o que contraria o objetivo dos programas de acompanhamento aos egressos de MSE de oferecer um acompanhamento sem obrigatoriedade e sem um caráter sancionatório. Como implicação, alguns jovens têm dificuldades de compreender a finalidade do acompanhamento e consideram a participação nos programas como uma continuidade do cumprimento de uma MSE (Foppa, 2011).

A realização das etapas do fluxo, principalmente a apresentação dos programas aos jovens, possui um impacto positivo, que é reconhecido pelos membros da equipe técnica como um aspecto fundamental para propiciar a adesão, a vinculação e o pertencimento dos jovens, na medida em que esse é um momento de 
diálogo e não apenas de palestras, quando os jovens podiam fazer perguntas sobre o acompanhamento e a contribuição efetiva (Foppa, 2011). A apresentação da equipe técnica de referência que fará o acompanhamento posterior representa a possibilidade da vinculação dos jovens aos programas de acompanhamento, pois a qualidade da formação do vínculo de confiança implica na relação de pertencimento a ser construída com os programas e na viabilidade da construção e efetivação dos projetos de vida dos jovens, considerando que não depende exclusivamente dos jovens, mas da relação construída com outras gerações que atuam como referência nessa construção e são responsáveis por realizar a mediação entre eles e os direitos sociais (Mota, 2016).

Identificou-se que os programas de acompanhamentos aos egressos de MSE se orientam pelo princípio incompletude institucional, considerando o acesso às políticas sociais existentes no território e a realização do trabalho em rede a partir da articulação e mediação das políticas de educação, saúde, trabalho, cultura, lazer, esportes e segurança, que são eixos definidos no documento do Sinase e incorporados na pactuação do PIA egresso (Motti, 2015). Para isso, exige-se das equipes técnicas de referência a articulação permanente com as demais políticas sociais e com as unidades de execução de MSE (Barbosa \& Resende, 2014), de modo a garantir o estabelecimento de um fluxo por meio da realização de um acompanhamento com objetivos bem definidos e ampliar a esses jovens as possibilidades de exercer a proteção integral (Motti, 2015), assim como auxiliar aqueles que tenham vivenciado longos períodos de internação na construção da autonomia e no gerenciamento da própria vida (Gonçalves, 2017).

$\mathrm{O}$ trabalho em rede, enquanto metodologia que orienta as ações dos programas de egressos de MSE, busca mediar o acesso dos jovens acompanhados às demais políticas sociais setoriais, o que, na ausência dessa intervenção, não ocorreria de forma direta. Dentre os programas de acompanhamento aos egressos de MSE analisados, identificou-se que os que se encontram consolidados possuem uma trajetória de trabalho em rede que objetiva e proporciona o desenvolvimento da autonomia dos jovens, de modo que eles passem a depender cada vez menos dos programas e consigam acessar seus direitos, assim como fortalece a relação entre as políticas setorializadas e o sistema de justiça (Gonçalves \& Guará, 2010). No desenvolvimento do trabalho em rede pelos programas de acompanhamento a egressos em fase consolidada, há a utilização do PIA, cujo uso tem início nas unidades de MSE e é atualizado pelos programas de acompanhamento após a adesão do jovem (Foppa, 2011). No trabalho em rede, o PIA exerce a função de itinerário individualizado que elenca necessidades, interesses e prioridades dos jovens, além de configurar um instrumento com a potencialidade de garantir os direitos, a partir da pactuação com as demais política sociais (Barbosa \& Resende, 2014).

Um dos aspectos que justificam a necessidade do trabalho em rede são as dificuldades de acesso imediato dos jovens às políticas sociais, principalmente no que se refere ao estigma enfrentado por eles após a extinção do cumprimento da MSE, pois as políticas sociais têm recepcionado mal os jovens, dificultando ou impedindo a matrícula nas escolas e omitindo vagas nos postos de trabalho e em cursos de profissionalização (Ferraz, 2013). Desse modo, a necessidade da existência de programas de acompanhamento aos egressos de MSE se justifica como forma de garantir o acesso aos direitos sociais, que já foram profundamente negados em suas trajetórias de vida e durante o cumprimento da MSE.

\section{Considerações finais}

Diante do objetivo deste artigo de caracterizar os programas de acompanhamento aos jovens egressos de medida socioeducativa de internação, pode-se compreender que eles apresentam características diversas nos diferentes estados visitados, a partir das decisões de cada entidade executora das medidas socioeducativas de meio fechado, o que faz com que eles não se constituam como uma política nacional e de caráter universal. Consequentemente, os programas têm enfrentado desafios em sua implantação e permanência, como a falta de recursos voltados a sua manutenção, relacionada à precarização das políticas sociais, que se apresentam de forma setorializada e parcializada.

Outra questão analisada é a ausência de diretrizes específicas dos programas de acompanhamento aos egressos de MSE, dentro da política de socioeducação, o que se reflete na ausência de projetos políticos pedagógicos e na diversidade de objetivos e perspectivas teóricas assumidas pelos diferentes estados, que ora parecem exercer a função de continuidade de uma MSE. Portanto, não cumprem a função de promoção da autonomia dos jovens, compreendida aqui como a finalidade desse acompanhamento. 
Apesar das dificuldades, considera-se que a existência desses programas tem possibilitado a qualificação do atendimento da política de socioeducação, na medida em que tem operado como articuladora das políticas sociais, efetivando o princípio da incompletude institucional por meio do trabalho em rede. Os dados aqui discutidos podem trazer contribuições para os programas de acompanhamentos aos egressos de MSE que estão em processo de criação e implementação, na medida em que mostraram indicações de como essa política vem sendo executada pelos estados, apesar da pouca definição sobre como deve se dar seu funcionamento. Destaca-se, a partir do conjunto de informações analisadas, que o objetivo dos programas de acompanhamento aos egressos de MSE deve pautar-se na perspectiva da construção da autonomia dos jovens e não da ressocialização. Desse modo, a diminuição da reincidência pode ser considerada como uma consequência do acompanhamento prestado e não como a finalidade principal dessa política.

\section{Referências}

Abrantes, A. A., \& Bulhões, L. (2016). Idade adulta e o desenvolvimento psíquico na sociedade de classes: juventude e trabalho. In L. M. Martins, A. A. Abrantes \& M. G. D. Facci (Orgs.), Periodização histórico-cultural do desenvolvimento psíquico (pp. 241-265). Autores Associados.

Agum, R., Riscado, P., \& Menezes, M. (2015). Políticas Públicas: conceitos e análise em revisão. Revista Agenda Política, 3(2), 12-42. http://www.agendapolitica.ufscar.br/index.php/agendapolitica/article/view/67

Amorim, T. R. S. (2018). A justiça restaurativa na política de socioeducação: concepções, crítica e possibilidades [Tese de doutorado, Programa de Pós-graduação em Psicologia Social. Universidade Federal da Paraíba, João Pessoa, PB, Brasil]. https://repositorio.ufpb.br/jspui/handle/123456789/13452

Araújo, A. C. (2017). Efeitos do cumprimento de medida socioeducativa em meio aberto: uma análise a partir da perspectiva de adolescentes egressos em Natal-RN [Dissertação de Mestrado, Programa de Pós-Graduação em Psicologia, Universidade Federal do Rio Grande do Norte, Natal, RN, Brasil]. https://repositorio.ufrn.br/jspui/ handle/123456789/23679

Barbosa, M. C., \& Resende, G. S. L. (2014). A política do egresso da medida socioeducativa de internação no município de Barra do Garças - MT. Revista Panorâmica On-Line, 16, 94-109. http://revistas.cua.ufmt.br/revista/ index.php/revistapanoramica/article/view/574/225

Behring, E. R., \& Boschetti, I. (2006). Política Social: fundamentos e história. Cortez.

Brancaleon, B. B., Yamanaka, J. S., Castro, J. M., Cuoghi, K. G. \& Paschoalotto, M. A. C. (2015). Políticas públicas: conceitos básicos [Material de apoio desenvolvido para apresentação de discentes da disciplina Didática ministrada por Irene Kazumi Miura na Universidade de São Paulo].

Chimin Junior, A. B., Lavoratti, C., Moreira, D., Schultz, E. S., Bach, F. R., Budny, G., Silva, L., Krainski, L. B., Angreves, M. B., Ribeiro, M. M., \& Pacheco, M. (2008). Apoio familiar aos adolescentes egressos do sistema sócio-educativo da região de Ponta Grossa - PR. Revista Conexão UEPG, 4(1), 22-27. http://www.revistas2.uepg.br/ index.php/conexao/article/view/3799/2685

Conselho Nacional de Justiça. (2012). Panorama Nacional: A Execução das Medidas Socioeducativas de Internação: Programa Justiça ao Jovem. https://www.cnj.jus.br/wp-content/uploads/2011/02/panorama_nacional_ doj_web.pdf

Ferrão, I. S., Santos, S. S., \& Dias, A. C. G. (2016). Psicologia e práticas restaurativas na socioeducação: Relato de Experiência. Psicologia: Ciência e Profissão, 36(2), 354-363 https://www.redalyc.org/articulo.oa?id=282046232010

Ferraz, A. L. (2013). A reinserção social dos jovens egressos da fundação de atendimento socioeducativo no município de Osório/RS [Dissertação do Mestrado, Programa de Mestrado Profissional em Inclusão Social e Acessibilidade, Universidade Feevale, Novo Hamburgo, RS, Brasil]. http://biblioteca.feevale.br/Dissertacao/ DissertacaoAndreiaFerraz.pdf

Foppa, G. M. (2011). Adolescente egresso da Fase: estudo de caso sobre o Programa RS socioeducativo [Dissertação de mestrado, Programa de Pós-Graduação em Ciências Criminais. Pontifícia Universidade Católica do Rio Grande do Sul, Porto Alegre, RS, Brasil]. http://hdl.handle.net/10923/1807

Gonçalves, A. S., \& Guará, I. M. F. R. (2010). Redes de proteção social na comunidade. Por uma nova cultura de articulação e cooperação em rede. In I. M. R. Guará (Org.), Redes de proteção social (pp. 11-20). Associação Fazendo História; Associação dos Pesquisadores de Núcleos de Estudos e Pesquisas sobre a Criança e o Adolescente. 
Gonçalves, R. T. (2017). Entre o mundão e a casa: a passagem pelo centro de atendimento socioeducativo ao adolescente (Fundação Casa) e a aproximação aos códigos e procederes do sistema prisional. Dilemas: Revista de estudos de conflito e controle social, 10(3), 449-478. https://revistas.ufrj.br/index.php/dilemas/article/ view/14559/9819

Jimenez, L., Jesus, N. F., Malvasi, P. A., \& Salla, F. (2012). Significados da nova lei do SINASE no sistema socioeducativo. Revista Brasileira Adolescência e Conflitualidade, 6, 01-18.

Lei n. 8.069, de 13 de julho de 1990. (1990). Dispõe sobre o Estatuto da Criança e do Adolescente e dá outras providências. Diário Oficial da União de 16 de julho de 1990.

Lei n. 8.742, de 7 de dezembro de 1993. (1993). Dispõe sobre a organização da Assistência Social e dá outras providências. Diário Oficial da União de 08 de dezembro de 1993.

Lei n. 12.594, de 18 de janeiro de 2012. (2012). Institui o Sistema Nacional de Atendimento Socioeducativo (Sinase), regulamenta a execução das medidas socioeducativas destinadas a adolescente que pratique ato infracional. Diário Oficial da União de 19 de janeiro de 2012.

Marinho, F. C., \& Galinkin, A. L. (2017). A história das práticas diante do desvio social de jovens no Brasil: reflexõessobreoidealderessocialização. Pesquisasepráticaspsicossociais, 12(2),280-297.http://pepsic.bvsalud.org/ scielo.php?script=sci_arttext\&pid=S1809-89082017000200004\&lng=pt\&tlng=pt

Minayo, M. C. S. (2014). O desafio do conhecimento: Pesquisa qualitativa em saúde (14a ed.). Hucitec.

Miranda, A. A. B., Aguinsky, B. G., Costa, C., Avila, L. F., Silva, M. J. J. C., \& Marques, S. M. M. (2014). Adolescentes em conflito com a lei e direitos humanos: desafios para implementação do Sinase. Revista de Políticas Públicas, 18(n.spe) 369-378. http://dx.doi.org/10.18764/2178-2865.v18nEp369-378

Mota, E. B. (2016). A socioeducação nos tempos de cólera. Revista EPOS, 7(2), 42-54. http://pepsic.bvsalud.org/ scielo.php?script=sci_arttext\&pid=S2178-700X2016000200004\&lng=pt\&tlng=pt

Motti, A. (2015). A incompletude institucional na execução das medidas socioeducativas. In P. C. D. Paes, M. F. Adimari \& R. P. Costa (Orgs.), Socioeducação e intersetorialidade: formação continuada de socioeducadores (pp. 17-24). Editora UFMS.

Nardi, F. L., \& Dell'Aglio, D. D. (2014). Trajetória de adolescentes em conflito com a lei após cumprimento de medida socioeducativa em meio fechado. Psico, 45(4), 541-550. http:/ /dx.doi.org/10.15448/1980-8623.2014.4.12978

Netto, J. P. (2011). Capitalismo monopolista e serviço social (8a ed.). Cortez.

Pasqualini, J. C. (2016). A teoria histórico-cultural da periodização do desenvolvimento psíquico como expressão do método materialista dialético. In L. M Martins, A. A. Abrantes \& M. G. D. Facci (Orgs.), Periodização histórico-cultural do desenvolvimento psíquico (pp. 63-90). Autores Associados.

Prado, A. C. G. C. (2014). O jovem egresso do sistema socioeducativo e seu acesso a políticas sociais: como prossegue a história? [Dissertação de Mestrado, Universidade Estadual Paulista Júlio de Mesquita Filho, Franca, SP, Brasil]. https://repositorio.unesp.br/handle/11449/123185

Rua, M. G. (2009). Políticas públicas. UFSC.

Secretaria Especial dos Direitos Humanos \& Conselho Nacional dos Direitos da Criança e do Adolescente. (2006). Sistema Nacional De Atendimento Socioeducativo: SINASE. http://www.conselhodacrianca.al.gov.br/ sala-de-imprensa/publicacoes/sinase.pdf

\section{Cibele Soares da Silva Costa}

Psicóloga. Doutora e Mestra em Psicologia Social pela Universidade Federal da Paraíba (UFPB), João Pessoa - PB. Brasil.

E-mail: cibele_sscosta@yahoo.com.br

(1) https://orcid.org/0000-0002-7004-2818

\section{Maria de Fatima Pereira Alberto}

Pós-doutora em Psicologia pela Universidade Federal do Rio Grande do Norte (UFRN), Natal - RN. Brasil. Doutora em Sociologia pela Universidade Federal de Pernambuco (UFPE), Recife - PE. Brasil. Professora Titular do 
Departamento de Psicologia e do Programa de Pós-Graduação em Psicologia Social da Universidade Federal da Paraíba. Pesquisadora 1D do Conselho Nacional de Desenvolvimento Científico e Tecnológico (CNPq). Membro do GT Juventude e Resiliência da Associação Nacional de Pesquisa e Pós-graduação em Psicologia (ANPEPP). Coordenadora do Núcleo de Pesquisas e Estudos sobre o Desenvolvimento da Infância e Adolescência (NUPEDIA). E-mail: jfalberto89@gmail.com

(1) https://orcid.org/0000-0003-2515-9571

Endereço para envio de correspondência:

Universidade Federal da Paraíba, Campus I. Centro de Ciências Humanas Letras e Artes. Departamento de Psicologia. Núcleo de Pesquisas e Estudos sobre o Desenvolvimento da Infância e Adloescência (Ambiente dos professores, sala 25, $1^{\circ}$ andar). Loteamento Cidade Universitária. CEP: 58051-900. João Pessoa - PB. Brasil

Recebido 14/03/2019

Aceito 10/08/2020

Received 03/14/2019

Approved 08/10/2020

Recibido $14 / 03 / 2019$

Aceptado 10/08/2020

Como citar: Costa, C. S. da S., \& Alberto, M. de F. P. (2021). Caracterização dos Programas de Acompanhamento aos Jovens Egressos de Medidas Socioeducativas. Psicologia: Ciência e Profissão, 41, 1-16. https://doi.org/10.1590/ 1982-3703003221253

How to cite: Costa, C. S. da S., \& Alberto, M. de F. P. (2021). Characterization of Follow-up Programs for Young Egresses from Socio-educational Measures. Psicologia: Ciência e Profissão, 41, 1-16. https://doi.org/10.1590/ 1982-3703003221253

Cómo citar: Costa, C. S. da S., \& Alberto, M. de F. P. (2021). Caracterización de los Programas de Seguimiento a los Jóvenes Egresados de Medidas Socioeducativas. Psicologia: Ciência e Profissão, 41, 1-16. https://doi.org/10.1590/ 1982-3703003221253 